\title{
OPTIMIZATION OF PARAMETERS FOR RECYCLING OF STEEL PROCESS BY GREY TAGUCHI TECHNIQUE
}

\author{
ALLURKAR BASWARAJ. $S^{1} \&$ M. SREENIVASA RAO ${ }^{2}$ \\ ${ }^{I}$ Research Scholar, Department of ME, JNTU, Hyderabad, Telangana, India \\ ${ }^{2}$ Professor, Department of ME, JNTU College of Engineering, Hyderabad, Telangana, India
}

\begin{abstract}
Optimization of process parameters of multiple response characteristics on secondary steel recycling by using Grey Taguchi technique is presented in this paper. Response characteristics such as Tensile strength, Hardness and Energy Consumption are optimized during the process. The investigation was carried out by considering the significant process parameters like furnace temperature, sponge steel, scrap steel composition, TDS of water used and Quenching temperature of steel. Based on DOE, 46 experiments were conducted. The response characteristics are analyzed using Grey Taguchi and optimal combination of significant influential parameters are obtained. Based on the response table, process parameter furnace temperature has highest influence whereas scrap steel composition has the lowest influence on the output. According to the results of verification experiments, it was concluded that Taguchi Grey Relational Analysis can be efficiently used to find the optimal combination of significant input parameters to get enhanced output of objective function for secondary steel recycling process.
\end{abstract}

KEYWORDS: Steel Recycling, Grey Taguchi, GRC \& GRG

Received: Jun 01, 2017; Accepted: Jun 20, 2017; Published: Jul 04, 2017; Paper Id: IJMPERDAUG20176

\section{INTRODUCTION}

Higher amount of Tensile strength and Hardness are the important properties required in steels which are desired by customers. Secondary steel manufacturers aim to achieve the above objective functions by using less energy. By considering these two main objective functions, experimental analysis was carried out. The material selected is recycled steel rod of diameter $18 \mathrm{~mm}$. Experiments were conducted in a secondary steel plant. For the obtained results, Grey Taguchi technique is applied and critical analysis is presented for achieving better quality of secondary steel and improving the chosen objective function. The experimental values are nearly in agreement with the results obtained by Grey Taguchi technique.

Steel is the mostly used and recycled metal in the world. It is used in many industries like construction, automobile, machinery, transportation, surgical and healthcare, telecommunication etc., Steel is manufactured by integrated and recycling process. It is economically beneficial to recycle iron and steel by melting and casting to produce new steel. Recycling of steel makes more efficient use of the natural resources. Secondary steel is assumed to be inferior in quality, when compared to integrated steel. The aim of present work is to optimize the tensile strength, hardness of secondary steel by minimizing energy consumption. Modern optimization techniques like Grey Taguchi are used to achieve the desired objective. 


\section{PROCESS PARAMETERS IN SECONDARY STEEL RECYCLING}

A thorough understanding of the inter-relationship between the various parameters is a very crucial factor in producing steel from scrap with good quality. There are many parameters which affect the quality of steel. After careful investigation of the secondary steel making process, the most significant affecting parameters are identified to be five in number. They are the furnace temperature (Ft), sponge steel (SS) added to input charge, scrap steel composition (SCS), TDS of water used for quenching (TDS) and temperature of steel bar after quenching (Qw) which comes out of the mould.

\section{Issues in Secondary Steel Recycling Process}

In the process of steel recycling, difficulties are encountered in setting optimal process conditions to minimize defects and increase tensile strength, hardness and at the same time, energy consumption and defects should be less. Manual regulatory control completely depends on human cognition, which has the capability to generate faulty results. This may lead to variation in the desired objective function. Factors like increased complexity of the system, more quality requirements and increase in the cost of resources also play a vital role. In order to achieve the above objective functions, Grey Taguchi technique is used.

\section{METHODOLOGY: GREY RELATIONAL ANALYSIS}

Grey Taguchi method was used to ascertain the optimization of process parameters in making steel bars for better quality in secondary steel making. Taguchi based Grey Relational analysis is actually a Design of Experiment (DOE) approach to create best combination of experimental variables to get desired response variable. If the target values are multiple in numbers, then Grey Taguchi method is to be used. As in the present case of experimentation, the objective functions are three in number like tensile strength and hardness and energy consumption.

Table 1: Input Parameters with Levels for Experimentation

\begin{tabular}{|l|c|c|c|}
\hline Sr. No & Level 1 & Level 2 & Level 3 \\
\hline Ft & 1650 & 1675 & 1700 \\
\hline SS & 10 & 12.5 & 15 \\
\hline SCS & 75 & 80 & 85 \\
\hline TDS & 30 & 35 & 40 \\
\hline Qw & 500 & 525 & 550 \\
\hline
\end{tabular}

\section{EXPERIMENTATION}

By using design of experiments, various combinations of levels for all the five parameters are generated. Experiments are conducted for all the 46 arrays and the corresponding values of hardness number, tensile strength and energy consumption are noted and tabulated as shown below. The units for hardness are Brinell hardness number, tensile strength in $\mathrm{N} / \mathrm{mm}^{2}$ and energy consumption in Kilo watt hour (KwH). By using Grey Taguchi method normalization, grey relational coefficient, grey relational grades for all the parameters is calculated and then based on the Grey Relational Grades, all the experiments have appropriately ranked and are shown in Table. 2 below. The experiments were conducted in a secondary steel plant, which uses scrap steel to 
manufacture steel bars of $18 \mathrm{~mm}$ diameter. For every set of parameters, sample of steel bar manufactured in that lot is tested on universal testing machine of 10 tonne capacity for Tensile Strength, Brinell hardness testing machine for testing hardness number and Energy meter readings are noted for measuring energy consumption rate for every set of output response.

Table 2: Parameters, Responses with Normalizing, Coefficients, Grading with Ranking

\begin{tabular}{|c|c|c|c|c|c|c|c|c|c|c|c|c|c|c|c|c|}
\hline $\begin{array}{l}\text { Ex. } \\
\text { No. } \\
\end{array}$ & Ft & SS & SCS & TDS & Qw & HS & TS & En.Con. & HGRN & TGRN & EGRN & HGRC & TGRC & EGRC & GRG & Rank \\
\hline 1 & 1675 & 12.5 & 75 & 35 & 550 & 105 & 623 & 360.1 & 0.59 & 0.53 & 0.45 & 0.55 & 0.52 & 0.48 & 0.51 & 32 \\
\hline 2 & 1675 & 12.5 & 80 & 40 & 550 & 104 & 620 & 359.8 & 0.54 & 0.47 & 0.44 & 0.52 & 0.48 & 0.47 & 0.49 & 35 \\
\hline 3 & 1675 & 12.5 & 80 & 35 & 525 & 105 & 624 & 359.4 & 0.69 & 0.55 & 0.41 & 0.62 & 0.53 & 0.46 & 0.53 & 22 \\
\hline 4 & 1700 & 12.5 & 75 & 35 & 525 & 107 & 641 & 367.1 & 0.93 & 0.91 & 0.91 & 0.88 & 0.85 & 0.85 & 0.86 & 6 \\
\hline 5 & 1675 & 15 & 80 & 35 & 500 & 105 & 638 & 358.8 & 0.66 & 0.85 & 0.37 & 0.59 & 0.77 & 0.44 & 0.6 & 11 \\
\hline 6 & 1675 & 12.5 & 75 & 35 & 500 & 104 & 629 & 359.2 & 0.51 & 0.66 & 0.4 & 0.5 & 0.59 & 0.45 & 0.52 & 28 \\
\hline 7 & 1675 & 12.5 & 85 & 35 & 550 & 106 & 621 & 359.3 & 0.75 & 0.49 & 0.4 & 0.67 & 0.49 & 0.46 & 0.54 & 16 \\
\hline 8 & 1675 & 12.5 & 80 & 30 & 550 & 105 & 628 & 359.6 & 0.57 & 0.64 & 0.42 & 0.54 & 0.58 & 0.46 & 0.53 & 25 \\
\hline 9 & 1650 & 10 & 80 & 35 & 525 & 101 & 598 & 354 & 0 & 0 & 0.06 & 0.33 & 0.33 & 0.35 & 0.34 & 46 \\
\hline 10 & 1700 & 12.5 & 85 & 35 & 525 & 107 & 643 & 367.1 & 1 & 0.96 & 0.91 & 1 & 0.92 & 0.85 & 0.92 & 2 \\
\hline 11 & 1700 & 12.5 & 80 & 35 & 500 & 107 & 645 & 367.5 & 0.95 & 1 & 0.94 & 0.91 & 1 & 0.89 & 0.93 & 1 \\
\hline 12 & 1700 & 15 & 80 & 35 & 525 & 107 & 643 & 365.5 & 1 & 0.96 & 0.81 & 1 & 0.92 & 0.72 & 0.88 & 4 \\
\hline 13 & 1650 & 12.5 & 80 & 35 & 500 & 102 & 610 & 355.5 & 0.15 & 0.26 & 0.16 & 0.37 & 0.4 & 0.37 & 0.38 & 41 \\
\hline 14 & 1675 & 12.5 & 80 & 30 & 500 & 105 & 630 & 359.1 & 0.57 & 0.68 & 0.39 & 0.54 & 0.61 & 0.45 & 0.53 & 24 \\
\hline 15 & 1675 & 12.5 & 80 & 35 & 525 & 105 & 628 & 358.1 & 0.69 & 0.64 & 0.32 & 0.62 & 0.58 & 0.43 & 0.54 & 17 \\
\hline 16 & 1675 & 12.5 & 75 & 40 & 525 & 105 & 625 & 362.6 & 0.67 & 0.57 & 0.62 & 0.6 & 0.54 & 0.57 & 0.57 & 14 \\
\hline 17 & 1675 & 10 & 80 & 40 & 525 & 104 & 614 & 362.3 & 0.43 & 0.34 & 0.6 & 0.47 & 0.43 & 0.55 & 0.48 & 36 \\
\hline 18 & 1675 & 15 & 85 & 35 & 525 & 105 & 634 & 359 & 0.67 & 0.77 & 0.38 & 0.6 & 0.68 & 0.45 & 0.58 & 13 \\
\hline 19 & 1675 & 12.5 & 80 & 35 & 525 & 105 & 626 & 361 & 0.61 & 0.6 & 0.51 & 0.56 & 0.55 & 0.51 & 0.54 & 21 \\
\hline 20 & 1675 & 15 & 75 & 35 & 525 & 105 & 642 & 359.1 & 0.67 & 0.94 & 0.39 & 0.6 & 0.89 & 0.45 & 0.65 & 9 \\
\hline 21 & 1700 & 12.5 & 80 & 30 & 525 & 107 & 641 & 367.1 & 0.95 & 0.91 & 0.91 & 0.91 & 0.85 & 0.85 & 0.87 & 5 \\
\hline 22 & 1675 & 15 & 80 & 30 & 525 & 105 & 638 & 357.6 & 0.69 & 0.85 & 0.29 & 0.62 & 0.77 & 0.41 & 0.6 & 12 \\
\hline 23 & 1675 & 12.5 & 85 & 30 & 525 & 105 & 626 & 359.1 & 0.67 & 0.6 & 0.39 & 0.6 & 0.55 & 0.45 & 0.54 & 18 \\
\hline 24 & 1675 & 10 & 80 & 30 & 525 & 104 & 617 & 361.7 & 0.44 & 0.4 & 0.56 & 0.47 & 0.46 & 0.53 & \begin{tabular}{|c|}
0.49 \\
\end{tabular} & 34 \\
\hline 25 & 1650 & 12.5 & 75 & 35 & 525 & 102 & 608 & 354.3 & 0.15 & 0.21 & 0.08 & 0.37 & 0.39 & 0.35 & \begin{tabular}{|l|}
0.37 \\
\end{tabular} & 42 \\
\hline 26 & 1675 & 10 & 80 & 35 & 500 & 105 & 618 & 362.9 & 0.56 & 0.43 & 0.64 & 0.53 & 0.47 & 0.58 & 0.52 & 26 \\
\hline 27 & 1700 & 10 & 80 & 35 & 525 & 106 & 632 & 368.5 & 0.87 & 0.72 & 1 & 0.79 & 0.64 & 1 & 0.81 & 8 \\
\hline 28 & 1675 & 12.5 & 80 & 35 & 525 & 105 & 627 & 358.2 & 0.56 & 0.62 & 0.33 & 0.53 & 0.57 & 0.43 & 0.51 & 31 \\
\hline 29 & 1700 & 12.5 & 80 & 40 & 525 & 107 & 642 & 367.9 & 0.95 & 0.94 & 0.96 & 0.91 & 0.89 & 0.93 & 0.91 & 3 \\
\hline 30 & 1650 & 12.5 & 80 & 35 & 550 & 102 & 604 & 354 & 0.2 & 0.13 & 0.06 & 0.38 & 0.36 & 0.35 & 0.36 & 45 \\
\hline 31 & 1675 & 10 & 85 & 35 & 525 & 104 & 621 & 361.4 & 0.51 & 0.49 & 0.54 & 0.5 & 0.49 & 0.52 & 0.51 & 30 \\
\hline 32 & 1675 & 15 & 80 & 35 & 550 & 105 & 634 & 358.5 & 0.66 & 0.77 & 0.35 & 0.59 & 0.68 & 0.44 & 0.57 & 15 \\
\hline 33 & 1650 & 12.5 & 80 & 40 & 525 & 102 & 608 & 353.1 & 0.13 & 0.21 & 0 & 0.37 & 0.39 & 0.33 & 0.36 & 44 \\
\hline 34 & 1650 & 12.5 & 80 & 30 & 525 & 102 & 606 & 353.5 & 0.2 & 0.17 & 0.03 & 0.38 & 0.38 & 0.34 & 0.37 & 43 \\
\hline 35 & 1675 & 12.5 & 80 & 35 & 525 & 105 & 632 & 358.4 & 0.57 & 0.72 & 0.34 & 0.54 & 0.64 & 0.43 & $\begin{array}{l}0.54 \\
\end{array}$ & 19 \\
\hline 36 & 1675 & 10 & 80 & 35 & 550 & 104 & 610 & 361.9 & 0.44 & 0.26 & 0.57 & 0.47 & 0.4 & 0.54 & 0.47 & 38 \\
\hline 37 & 1675 & 15 & 80 & 40 & 525 & 105 & 640 & 359.2 & 0.66 & 0.89 & 0.4 & 0.59 & 0.82 & 0.45 & 0.62 & 10 \\
\hline 38 & 1675 & 12.5 & 80 & 35 & 525 & 105 & 624 & 360 & 0.61 & 0.55 & 0.45 & 0.56 & 0.53 & 0.48 & 0.52 & 27 \\
\hline 39 & 1650 & 12.5 & 85 & 35 & 525 & 102 & 607 & 354.7 & 0.21 & 0.19 & 0.1 & 0.39 & 0.38 & 0.36 & 0.38 & 40 \\
\hline 40 & 1675 & 12.5 & 75 & 30 & 525 & 104 & 628 & 359.6 & 0.44 & 0.64 & 0.42 & 0.47 & 0.58 & 0.46 & 0.51 & 29 \\
\hline 41 & 1700 & 12.5 & 80 & 35 & 550 & 107 & 639 & 367 & 0.93 & 0.87 & 0.9 & 0.88 & 0.8 & 0.84 & 0.84 & 7 \\
\hline 42 & 1675 & 12.5 & 80 & 40 & 500 & 104 & 626 & 361.2 & 0.52 & 0.6 & 0.53 & 0.51 & 0.55 & 0.51 & 0.53 & 23 \\
\hline 43 & 1675 & 10 & 75 & 35 & 525 & 104 & 615 & 362 & 0.41 & 0.36 & 0.58 & 0.46 & 0.44 & 0.54 & 0.48 & 37 \\
\hline 44 & 1675 & 12.5 & 85 & 40 & 525 & 105 & 621 & 358.9 & 0.57 & 0.49 & 0.38 & 0.54 & 0.49 & 0.45 & 0.49 & 33 \\
\hline 45 & 1675 & 12.5 & 85 & 35 & 500 & 104 & 629 & 361.7 & 0.46 & 0.66 & 0.56 & 0.48 & 0.59 & 0.53 & 0.54 & 20 \\
\hline 46 & 1650 & 15 & 80 & 35 & 525 & 103 & 619 & 353.3 & 0.25 & 0.45 & 0.01 & 0.4 & 0.47 & 0.34 & 0.4 & 39 \\
\hline
\end{tabular}

\section{Grey Relational Generation}

It is important to process all experimental values for each option into a similarity arrangement, in a procedure comparable to standardization. This preparation is called generating of grey relation in GRA.

For Higher-the-better quality, normalizing data is calculated by 


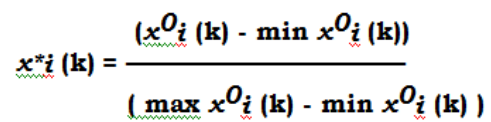

For Lower-the-better quality, normalizing data is calculated by

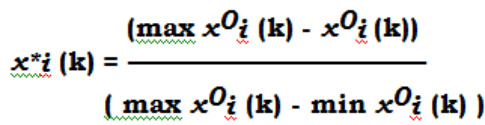

$\mathrm{k}=1$ to $\mathrm{n}, \mathrm{i}=1$ to 9 ; "n" is the performance characteristic and "i $\mathbf{i}$ " is the trial number

$\boldsymbol{x} * \boldsymbol{i} \rightarrow$ is the sequence after data normalizing

$\boldsymbol{x}_{\boldsymbol{0}} \boldsymbol{i} \rightarrow$ is the original sequence

$\max x^{0_{i}}(\mathbf{k}) \rightarrow$ is the largest value of $x^{O} i(\mathrm{k})$

$\min x^{0}(\mathbf{k}) \rightarrow$ is the smallest value of $x^{0} i(\mathrm{k})$

The grey relational coefficient is calculated from the normalized experimental data to express the relationship between the ideal and the actual experiment.

$\mathrm{I}(\mathrm{k})$ for the $\mathrm{K}_{\mathrm{th}}$ Performance characteristics in $\mathrm{i}_{\mathrm{th}}$ experiment is

$$
\begin{aligned}
& \mathrm{I}(\mathrm{K})=\left(\Delta_{\min +} \Psi \Delta_{\max }\right) /\left(\Delta_{\mathrm{oi}+} \Psi \Delta_{\max }\right) \\
& \Delta_{\mathrm{oi}=}\left\|\mathrm{x}^{*}{ }_{0}(\mathrm{k})-\mathrm{x}_{\mathrm{i}}{ }^{*}(\mathrm{k})\right\| \\
& \Delta_{\min }=\min \left\|x^{*} 0(\mathrm{k})-x^{*} i(\mathrm{k})\right\| \\
& \Delta_{\max }=\max \left\|x^{*} 0(\mathrm{k})-x^{*}{ }_{i}(\mathrm{k})\right\|
\end{aligned}
$$

Where,

$x * 0(\mathrm{k})$ is the reference sequence

$x * i(\mathrm{k})$ is the compatibility sequence

$\Psi$ is 0 to 1 , in general $\Psi=0.5$

The grey relational grade is computed by averaging the grey relational coefficients corresponding to each process response. The overall evaluation of the multiple process responses is based on the grey relational grade. High Grey relational grade gives the optimal solutions.

The grey relational grade is obtained by:

$$
y_{i}=\frac{1}{n} \sum_{k=1}^{n} \varepsilon_{i}(k)
$$

Where, yi is the grey relational grade and $\mathrm{n}$ is the number of performance characteristics. High grey relational 
grade gives the optimal conditions. The experiment numbers and the grades with the ranking of larger value of grey relation grade to smaller value are tabulated.

\section{RESULTS}

By applying Grey Taguchi technique to the experimental data, different characteristic indices are obtained. These indices are shown in table.2. It is observed that Experiment No.11 has the highest Grey relation grade. The levels of parameters are highly influencing the quality of the steel manufactured. These corresponding parameters with levels of Furnace temperature $(\mathrm{Ft})$ at $1700^{\circ} \mathrm{C}$, Sponge Steel at $12.5 \%$, Scrap Steel Composition at $80 \%$, TDS of water used at 35 grade and Quenching of Steel at $500^{\circ} \mathrm{C}$ can be considered as optimal parameters that can be used for manufacturing quality steel according to Grey Taguchi method. The output obtained from these parameters are Tensile Strength $(\mathrm{Ts})=645 \mathrm{~N} / \mathrm{mm}^{2}$, Hardness value of steel $(\mathrm{Hs})=$ 107 and Energy Consumption (En. Con.) $=367.5 \mathrm{KwH}$.

Table 3: Response Table

\begin{tabular}{|c|c|c|c|c|c|}
\hline Level & Ft & SS & SCS & TDS & Qw \\
\hline 1 & 0.3702 & 0.5128 & 0.5583 & 0.5533 & 0.569 \\
\hline 2 & 0.5358 & 0.5751 & 0.5772 & 0.5799 & 0.5804 \\
\hline 3 & 0.8783 & 0.6129 & 0.5609 & 0.5574 & 0.5399 \\
\hline Delta & 0.508 & 0.1 & 0.0188 & 0.0266 & 0.0405 \\
\hline Rank & 1 & 2 & 5 & 4 & 3 \\
\hline
\end{tabular}

Response Table is generated as shown in Table.3. Based on the response table it is observed that Furnace Temperature is the most influencing factor, followed by Sponge steel, Quenching of steel, TDS of water and least influencing factor is scrap steel composition.

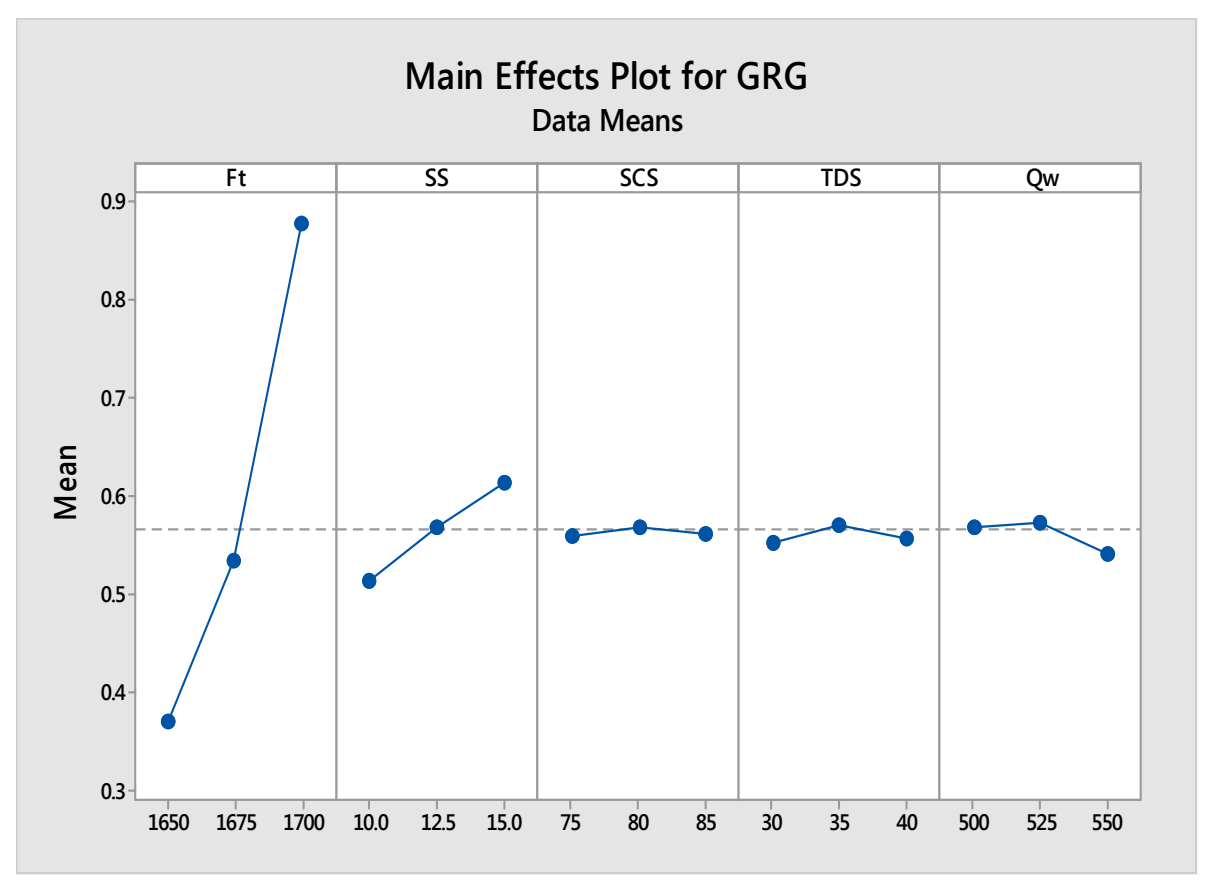

Figure 1: Main Effects Plot for Grey Relational Grade 
The main effect plot for GRG is as shown in figure.1.The ordinate of it represents the mean of grey relational grade calculated using larger - the - better criteria. From the main effect plot it can be stated that optimal value of the parameters through Grey Relational Grading is nearer to the values of experimental results. The higher the grey relational grade, the better are the performance characteristics. From the main effects plot graph, the optimal factor combination is determined. The graph generated shows the optimum combination of parameters with corresponding values.

\section{Confirmation of Results}

For the selection of optimal parameters with its levels to evaluate the quality characteristics for secondary steel recycling, a confirmation test has to be conducted. From the grey relational analysis it shows that the highest grey relation grade (GRG) indicating the initial process parameter set of (A3 B3 C2D2E2) for the best multiple performance characteristics among the forty six experiments.

The optimal grey relational grade (GRGopt) is predicted by using the following equation:

$$
G R G_{\text {opt }}=G R G_{\text {mean }}+\sum_{i=1}^{n}\left(G R G_{i}-G R G_{\text {mean }}\right)
$$

Where

$\mathrm{GRG}_{\text {mean }}$ is the average of Grey relational grade,

$\mathrm{GRG}_{\mathrm{i}}$ is the average of grey relational analysis at optimum level and

$\mathrm{n}$ is the significantly affecting process parameters.

The predicted value of optimal grey relational grade is expressed by taking $n=5$ since there are five significant parameters.

The predicted value of optimal Grey Relational Grade is calculated as

$\mathrm{GRG}_{\mathrm{opt}}=0.5547+(0.8783-0.5547)+(0.6129-0.5547)+(0.5772-0.5547)+(0.5799-0.5547)+(0.5804-0.5547)$

$=1.0$

Table 4: Experimental and Predicted Values of GRG

\begin{tabular}{|l|c|c|}
\hline $\begin{array}{l}\text { Optimal process } \\
\text { parameters }\end{array}$ & Predicted Value & Experimental Value \\
\hline Level & A3B3C2D2E2 & A3B2C2D2E1 \\
\hline HS & 107 & 107 \\
\hline TS & 643 & 645 \\
\hline $\begin{array}{l}\text { Energy } \\
\text { Consumption }\end{array}$ & 365.5 & 367.5 \\
\hline GRG & 1.0 & 0.93 \\
\hline
\end{tabular}

The GRG value obtained by conducting the experiments is nearer to the predicted values which are obtained by analytical formula.

\section{CONCLUSIONS}

This paper investigates the use of Taguchi Grey relational analysis for the optimization of process parameters on 
secondary steel recycling process of $16 \mathrm{~mm}$ diameter steel bar with multiple performance characteristics. This technique is more convenient and economical to predict the optimal machining parameters. Based on the results, the performance characteristics such as Hardness, Tensile strength and energy consumption can be improved through this approach. Experiments were conducted to confirm this approach. Based on the results of the experiments conducted and tests for confirmation of results, the following conclusions are drawn:

- The experimental results for optimal settings showed that there was a considerable improvement in the performance characteristics viz., Hardness and tensile strength and Energy Consumption.

- The most important factor affecting the secondary steel recycling process of steel bars has been identified as Furnace Temperature (Ft) followed by Sponge Steel (SS), Quenching Temperature (Qw), TDS of water and least influencing parameter is Scrap Steel Composition (SCS).

- The following factor settings have been identified as the best combination of process variables: A3B2C2D2E2

\section{REFERENCES}

1. Rahul Davis, 'Optimization of Surface Roughness in Wet Turning Operation of EN24 Steel', International Journal of Mechanical and Production Engineering Research and Development (IJMPERD), Vol.2, Issue 3, Sep 2012, $28-35$.

2. Morrison, C.T, et al, (1986). Erosion of 304 stainless steel. Wear 111, 1-13 lsdr33, Elsevier.

3. Raghuraman, et al., 'Optimization of EDM parameters using taguchi method and grey relational analysis for mild steel is 2026', International Journal of Innovative Research in Science, Engineering and Technology Vol. 2, Issue 7, July 2013, pp.3095-3104.

4. K. Sahoo, et al., 'Multi-response optimization in machining hardened steel using Grey-based Taguchi method', International Journal of Manufacturing Technology and Industrial Engineering, vol. 1, no. 1, June 2011, pp. 7-12.

5. P. Madhava Reddy, et al., 'Optimization of Machining Parameter For Turning Of EN 16 Steel Using Grey Based Taguchi Method', ARPN Journal of Engineering and Applied Sciences, Vol. 9, No. 3, March 2014, pp.216-222.

6. Umashankar M, et al., A Review on Optimization of Cutting Parameters in Machining Using Taguchi Method', International Journal of Innovative Research in Advanced Engineering, Volume 1 Issue 11, Nov. 2014, pp. 22 - 24.

7. A.R.Lande, et al., 'Gray Relational Based Analysis of Al-6351', IOSR Journal of Mechanical and Civil Engineering, Volume 12, Issue 6, Dec. 2015, PP 37-43.

8. Shadab Anwar, et al., 'Optimization of End Milling Parameters for Improving Surface Roughness Using Taguchi Method', International Journal of Mechanical and Production Engineering, Volume- 4, Issue-8, Aug.-2016, pp.6 - 9.

9. Finnie. 'Erosion of Surface by Solid Particles'. Welr, vol. 3, 1960.

10. P. Sreeraj, et al., 'Grey-Based Taguchi Method for Optimization of Heat Affected Zone in Flux Cored Arc Bead on Plate Welding', International Journal of Advanced Engineering Research and Studies, Vol.4, Dec.2014, pp. 46 - 53. 
